\title{
Diagnostic accuracy of a standardized scheme for identification of Streptococcus uberis in quarter milk samples: A comparison between conventional bacteriological examination, modified Rambach agar medium culturing, and 16S rRNA gene sequencing
}

\author{
Regina Wald, ${ }^{* 1}$ Martina Baumgartner, ${ }^{*}$ Verena Urbantke, ${ }^{*}$ Beatrix Stess,,$\dagger$ and Thomas Wittek* \\ *University Clinic for Ruminants, and \\ †Institute for Milk Hygiene, Milk Technology and Food Science, Department of Farm Animal and Public Health in Veterinary Medicine, \\ University of Veterinary Medicine, 1020 Vienna, Austria
}

\begin{abstract}
Bacteriological examination of milk samples is a prerequisite for pathogen-specific therapy and aids in limiting antimicrobial resistance. The aims of this study were to establish a standardized scheme for reliable Streptococcus uberis identification in routine diagnosis and to evaluate the accuracy of conventional tests and growing patterns of Strep. uberis on a selective medium (modified Rambach agar medium, MRAM) using 16S rRNA gene sequencing analysis as a reference method. We obtained isolates of presumptive Strep. uberis (n $=336$ ) from quarter milk samples of dairy cows with intramammary infections and classified the isolates into 2 clusters using biochemical characterization. In cluster $1(\mathrm{n}=280)$, cocci grew as non-hemolytic colonies, hydrolyzing esculin, carrying no Lancefield antigen (A/B/C/D/G) or Christie Atkins Munch-Petersen factor, and their growth was inhibited on an Enterococcus agar. Production of $\beta$-D-galactosidase on MRAM was shown by 257 of the cluster 1 isolates $(91.79 \%)$, and 16S rRNA gene sequencing verified $271(96.79 \%)$ of the isolates to be Strep. uberis. In 264 isolates (94.29\%), MRAM agreed with the sequencing results. In cluster $2(\mathrm{n}=56)$, isolates showed different characteristics: $37(66.07 \%)$ were $\beta$-D-galactosidase-positive, and based on $16 \mathrm{~S}$ sequencing results, $36(64.29 \%)$ were identified correctly as Strep. uberis using biochemical methods. Identification success in this group differed significantly between routine diagnosis and MRAM application: MRAM agreed with sequencing results in 47 isolates (83.93\%). To identify Strep. uberis and differentiate it from other lactic acid bacteria in routine diagnosis, we suggest using catalase reaction, hemolysis, esculin hydrolysis, and growth on enterococci agar. Isolates
\end{abstract}

Received July 27, 2016.

Accepted October 20, 2016.

${ }^{1}$ Corresponding author: Regina.Wald@vetmeduni.ac.at that show a typical biochemical profile can be identified satisfactorily with these tests. For Strep. uberis isolates with divergent patterns, application of MRAM as a follow-up test increased the diagnostic accuracy to $94.64 \%$.

Key words: Streptococcus uberis, mastitis, modified Rambach agar medium

\section{INTRODUCTION}

Streptococcus uberis is one of the most prevalent mastitis pathogens worldwide, with increasing importance in high-yield dairy herds (Zadoks et al., 2003; Raemy et al., 2013; Werner et al., 2014). Acute clinical mastitis cases and persistent chronic subclinical IMI have been described, leading to high SCC interrupted by repeated clinical flare-ups (McDougall et al., 2004; Milne et al., 2005; Wyder et al., 2011; Tassi et al., 2013). Recent research has revealed that Strep. uberis is one of a few pathogens in which extended intramammary treatment is associated with higher bacteriological cure rates (Krömker et al., 2010; Swinkels et al., 2014). Good veterinary practice to limit antimicrobial resistance requires accurate identification of the mastitis-causing pathogen to ensure the best selection of antibiotic agent, and in the case of Strep. uberis, extended use of those antibiotics to attempt a cure (Hillerton and Kliem, 2002; Oliver et al., 2003, 2004; Swinkels et al., 2014). Schukken et al. (2009) reported that streptococcal differentiation results in better use of antibiotics, shorter treatment duration (for some), and higher treatment success. In most routine diagnostic laboratories, catalase-negative, gram-positive, esculin hydrolyzing cocci that are nontypable by Lancefield antigen are classified as Strep. uberis (Fortin et al., 2003; Odierno et al., 2006; Raemy et al., 2013). However, use of molecular techniques has shown that not all Strep. uberis isolates meet these phenotypical and biochemical criteria (Odierno et al., 2006; Raemy et al., 2013). Additionally, Enterococcus spp. and some species of Lactococcus and Aerococcus 
can hydrolyze esculin and may show similar biochemical profiles (Teixeira et al., 1996; Fortin et al., 2003; Odierno et al., 2006; Wyder et al., 2011; Werner et al., 2014).

Molecular methods provide accurate identification of Strep. uberis: PCR protocols have been established for Strep. uberis identification, but multiplex PCR assays are preferred for mastitis diagnosis, because several pathogens can be tested in 1 step, directly from bovine milk (Lam et al., 2009; Britten, 2012). However, molecular methods cannot entirely replace classical bacteriology at present, because susceptibility testing according to Clinical and Laboratory Standards Institute guidelines (CLSI, 2014) requires bacterial culture. Unfortunately, accurate methods are still lacking for identification of Strep. uberis isolates with deviating patterns in routine diagnosis (Gillespie and Oliver, 2005; Raemy et al., 2013; Werner et al., 2014). Standard application of modified Rambach agar medium (MRAM), a chromogenic differential medium based on the substrates propylene glycol and 5-bromo-4-chloro-3indolyl- $\beta$-D-galactopyranoside, seems to be a promising option: Watts et al. (1993) found that 94.9\% $(\mathrm{n}=151)$ of selected Strep. uberis isolates were $\beta$-D-galactosidasepositive (blue colonies), and none of the isolates used propylene glycol (red colonies). However, to our knowledge, the sensitivity and specificity of MRAM have not been validated using molecular methods. The main aim of the study was to develop a standardized scheme for reliable Strep. uberis identification in routine diagnosis. We carried out the study in 2 phases. In the first step, we evaluated the accuracy of biochemical methods applied in routine diagnosis and growing patterns on MRAM using 16S rRNA gene sequencing analysis as a reference method, and determined the sensitivity and specificity of MRAM. In the second step, we further characterized isolates misidentified as Strep. uberis and assessed the accuracy of the combined use of biochemical characteristics and MRAM.

\section{MATERIALS AND METHODS}

\section{Collection of Isolates in Routine Mastitis Diagnosis, Identification, and Study Group Formation}

We obtained all isolates from the diagnostic laboratory of the Clinic for Ruminants of the University of Veterinary Medicine in Vienna (Austria). Isolates originated from single-quarter milk samples of cows with subclinical or clinical IMI collected between August 2014 and September 2015. All gram-positive, catalasenegative field isolates in this specified period, growing in pure culture on the primary isolation plate, were stored at $-80^{\circ} \mathrm{C}$ in a $15 \%$ (vol/vol) glycerol solution for recultivation and characterization.

Isolates were confirmed biochemically as presumptive Strep. uberis if they were catalase-negative, whitish, non-hemolytic colonies, hydrolyzing esculin (assessed with UV light), carrying no Lancefield antigen (A/B/ C/D/G) or Christie Atkins Munch-Petersen (CAMP) factor, and inhibited in growth on a selective differential medium for enterococci with addition of bile salts.

A total of 336 isolates identified as Strep. uberis by the veterinary laboratory were included in the study. Isolates were classified into 2 groups according to the criteria listed in Figure 1: group 1 isolates were those with identical biochemical reactions to a reference strain (Strep. uberis ATCC 700407), and group 2 isolates deviated from the reference strain in 1 characteristic or more (Figure 1).

To differentiate between Strep. uberis and other esculin-positive streptococci, we evaluated growth (colony size, shape texture) and colony staining on MRAM. The formula was prepared as described by Watts et al. (1993). Organisms that formed dark blue colonies were considered positive for $\beta$-D-galactosidase production. For further characterization, we used fermentation of inulin (phenol red indicator), growth in $6.5 \% \mathrm{NaCl}$ solution (bromocresol purple indicator) as suggested in the National Mastitis Council guide (NMC, 1999), and appearance on a lactobacilli de Man, Rogosa, and Sharpe (MRS) agar. All tests (Oxoid, Basingstoke, UK) were performed and evaluated by the same person using the same batch of products. Biochemical tests were incubated at $37^{\circ} \mathrm{C}$. After $24 \mathrm{~h}$, bacterial growth and color change were assessed.

\section{S rRNA Gene Sequence Analysis}

Sequencing of the $16 \mathrm{~S}$ rRNA gene was defined as a reference method to confirm the identity of all 336 bacterial isolates. We performed chelex-based DNA extraction (Walsh et al., 1991), and amplified fragments of bacterial $16 \mathrm{~S}$ rRNA genes by $\mathrm{PCR}$ with primers 616F (5'-AGAGTTTGATYMTGGCTC-3') and 1492R (5'-GGYTACCTTGTTACGACTT-3') according to Juretschko et al. (1998) and Lane (1991). Cycling conditions for the 16S rRNA gene amplification were as follows: $95^{\circ} \mathrm{C}$ for $5 \mathrm{~min}$, followed by 25 cycles of $94^{\circ} \mathrm{C}$ for $40 \mathrm{~s}$, annealing at $52^{\circ} \mathrm{C}$ for $40 \mathrm{~s}$, elongation at $72^{\circ} \mathrm{C}$ for $60 \mathrm{~s}$, and a final elongation at $72^{\circ} \mathrm{C}$ for $7 \mathrm{~min}$.

We examined the quality of PCR amplification products by visualization on 1.5\% agarose gel $(120 \mathrm{~V}, 30$ min) using fluorescent dye and UV light. Sequencing was performed at LGC Genomics (Berlin, Germany). Nucleotide sequences were trimmed using FinchTV 
(Geospinza, Seattle, WA). We performed similarity searches using the blast algorithm from the National Center for Biotechnology Information (https://blast. ncbi.nlm.nih.gov/Blast.cgi). Sequences with similarity values (nucleotide identity and query coverage) of $\geq 98 \%$ were considered to belong to the same species.

The partial rRNA gene sequence data analyzed in this study have been deposited in the GenBank database under accession numbers KX389930 to KX390233 and KX880952 to KX880983.

\section{Statistical Analysis}

We performed all calculations using SPSS Statistics 23.0 (IBM, Armonk, NY) and Excel 2013 (Microsoft Corporation, Redmond, WA). For all tests, statistical significance was defined at $P \leq 0.05$.

We compared the accordance of strain identification between 16S rRNA gene sequencing and bacteriological examination with MRAM using McNemar's chi-squared test. We computed Cohen's kappa ( $\boldsymbol{\kappa}$ ) statistics to es-

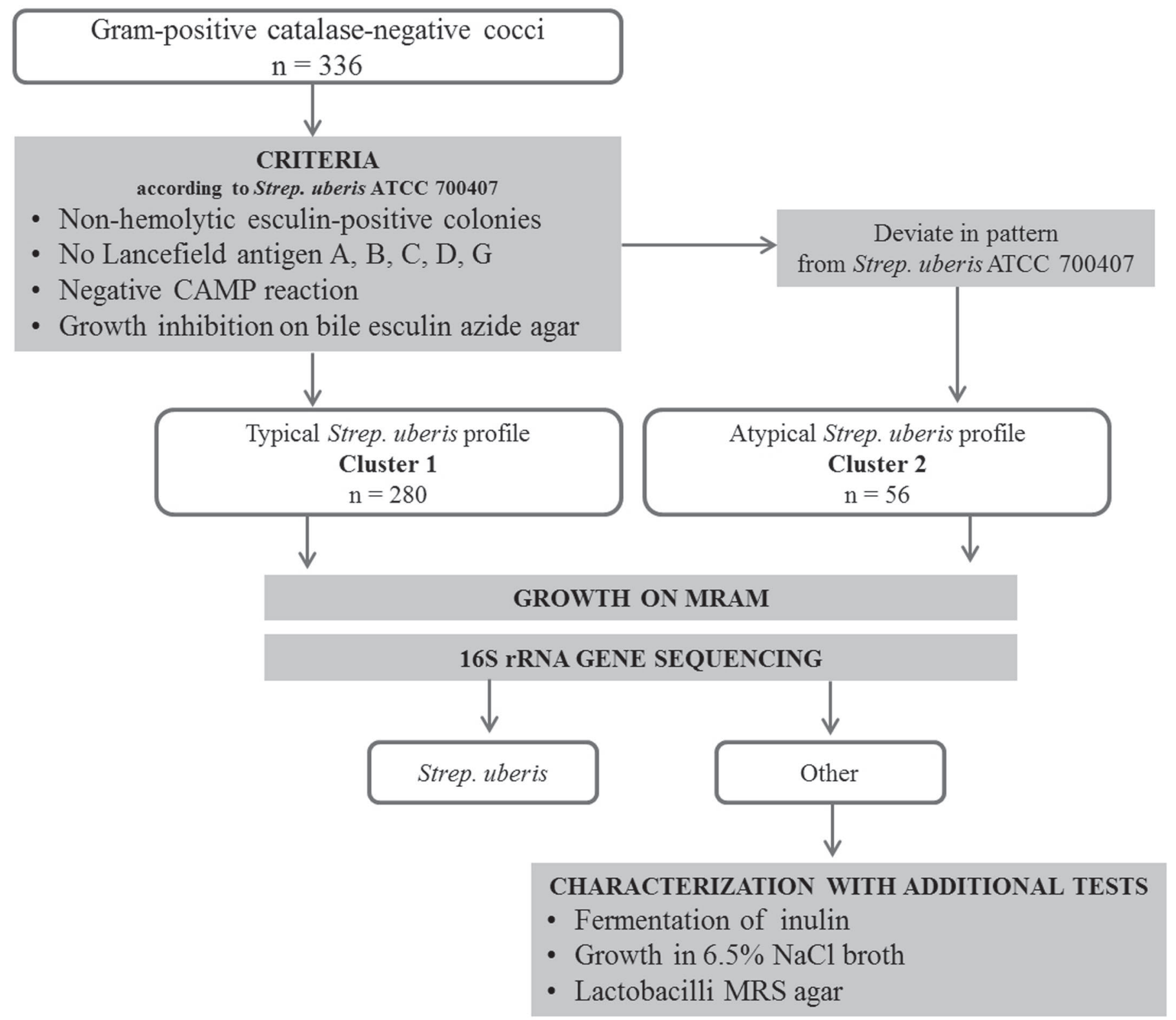

Figure 1. Schematic overview of the presumptive Streptococcus uberis isolates collected from August 2014 to September 2015 in routine diagnosis (decision tree). CAMP = Christie Atkins Munch-Petersen; MRAM = modified Rambach agar medium; MRS = de Man, Rogosa, and Sharpe. 
Table 1. Distribution of biochemical characteristics in cluster 1 (typical profile) and cluster 2 (deviating profile)

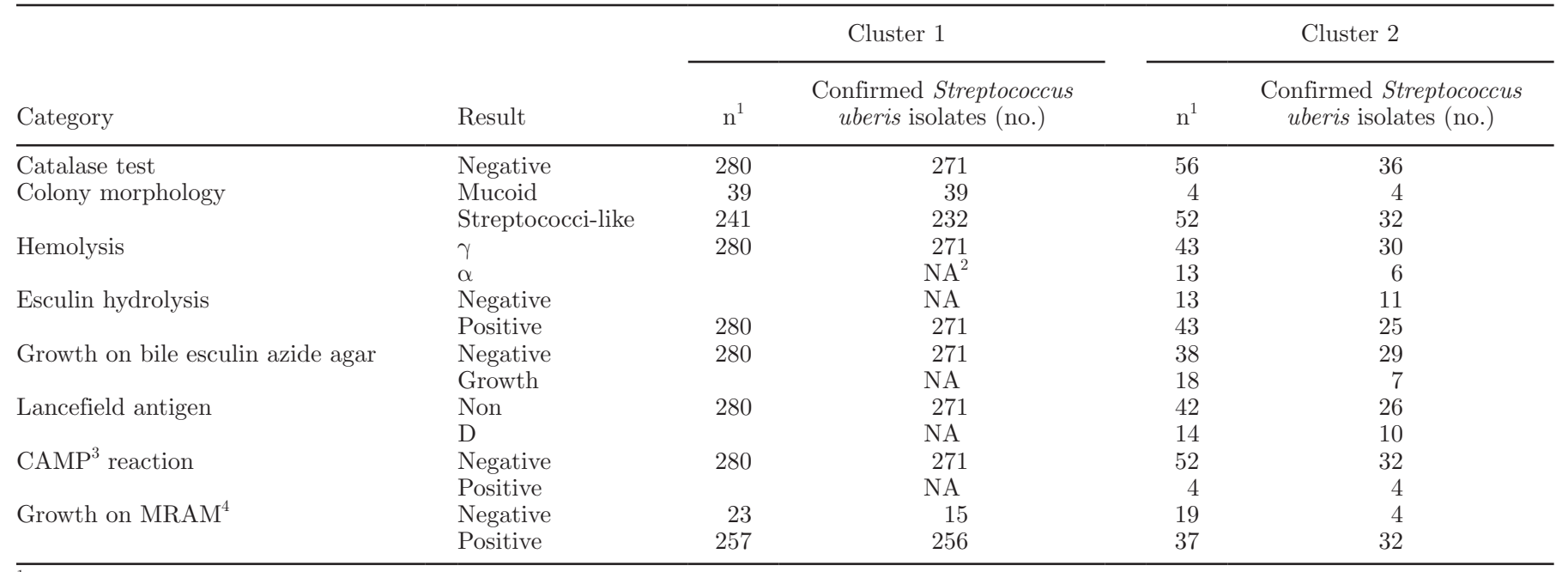

${ }^{1} \mathrm{n}=$ number of isolates.

${ }^{2} \mathrm{NA}=$ not applicable.

${ }^{3} \mathrm{CAMP}=$ Christie Atkins Munch-Petersen.

${ }^{4} \mathrm{MRAM}=$ modified Rambach agar medium.

timate agreement between (1) $16 \mathrm{~S}$ and bacteriological culture; (2) $16 \mathrm{~S}$ and MRAM; (3) bacteriological culture and MRAM; (4) $16 \mathrm{~S}$ and identification by one of those methods (either bacteriological culture or MRAM indicating Strep. uberis); or (5) $16 \mathrm{~S}$ and both (bacteriological culture plus MRAM) indicating Strep. uberis. Agreement was interpreted as good $(>0.79)$, substantial (0.60-0.79), moderate $(0.40-0.59)$, or fair (0.21-0.39) (McHugh, 2012). We used the area under the curve (AUC) and its 95\% confidence interval to compare discriminative capacity. An area of $\geq 0.90$ was considered excellent, $0.80-0.89$ was good, $0.70-0.79$ was fair, and $\leq 0.69$ was poor. We also calculated accuracy and $95 \%$ confidence interval for each cluster (1 and 2 ) and diagnostic procedure (bacteriological culture and MRAM), as well as the total accuracy for each method and for the combined use of biochemical testing and MRAM. For bacteriological culture and MRAM, we calculated sensitivity, specificity, positive predictive value, and negative predictive value for Strep. uberis detection using $16 \mathrm{~S}$ rRNA gene sequencing results as the reference method.

\section{RESULTS}

\section{Identification of the Bacterial Isolates with Conventional Tests and 16S rRNA Gene Sequencing}

We classified 280 of the 336 field isolates as Strep. uberis based on defined morphological and biochemical criteria (cluster 1 according to Strep. uberis ATCC
700407). These isolates in the typical biochemical profile cluster exhibited the same characteristics as the reference quality-control strain (Table 1). Of these isolates, 39 formed large mucoid and translucent colonies on sheep blood agar, differing substantially in colony appearance from non-mucoid-growing isolates. All mucoid colonies were confirmed as Strep. uberis with $16 \mathrm{~S}$ sequencing. Based on $16 \mathrm{~S}$ rRNA gene sequencing data, 271 of the 280 cluster 1 bovine isolates $(96.79 \%)$ were classified accurately to the species level by biochemical testing. Of the remainder, Lactococcus lactis $(\mathrm{n}=4)$, Lactococcus garvieae $(\mathrm{n}=3)$, and Streptococcus parauberis $(\mathrm{n}=2)$ were shown by $16 \mathrm{~S}$ rRNA gene sequencing to be incorrectly identified to the species level by routine diagnostic methods.

Fifty-six isolates differed in at least 1 biochemical reaction from the reference strain and were assigned to cluster 2 (Table 1). Of these, 36 were confirmed to be Strep. uberis by $16 \mathrm{~S}$ gene sequencing and 20 were identified as L. garvieae $(\mathrm{n}=6)$, Enterococcus $\mathrm{spp}$. ( $\mathrm{n}=$ 5), Weissella spp. $(\mathrm{n}=3)$, L. lactis $(\mathrm{n}=2)$, Aerococcus viridans, Streptococcus gallolyticus, Streptococcus henryi, and Streptococcus mitis (1 isolate each). For cluster 2 , the calculated accuracy between $16 \mathrm{~S}$ rRNA gene sequencing and conventional bacteriological examination was $64.29 \%$. Characteristics of the non-Strep. uberis isolates are presented in Table 2.

In total, 307 Strep. uberis isolates in clusters 1 and $2(91.73 \%)$ were correctly identified by conventional methods. The results of $16 \mathrm{~S}$ and bacteriological culture differed significantly (McNemar's test $P<0.001$ ). The $\kappa$ coefficient indicated an agreement between $16 \mathrm{~S}$ and 


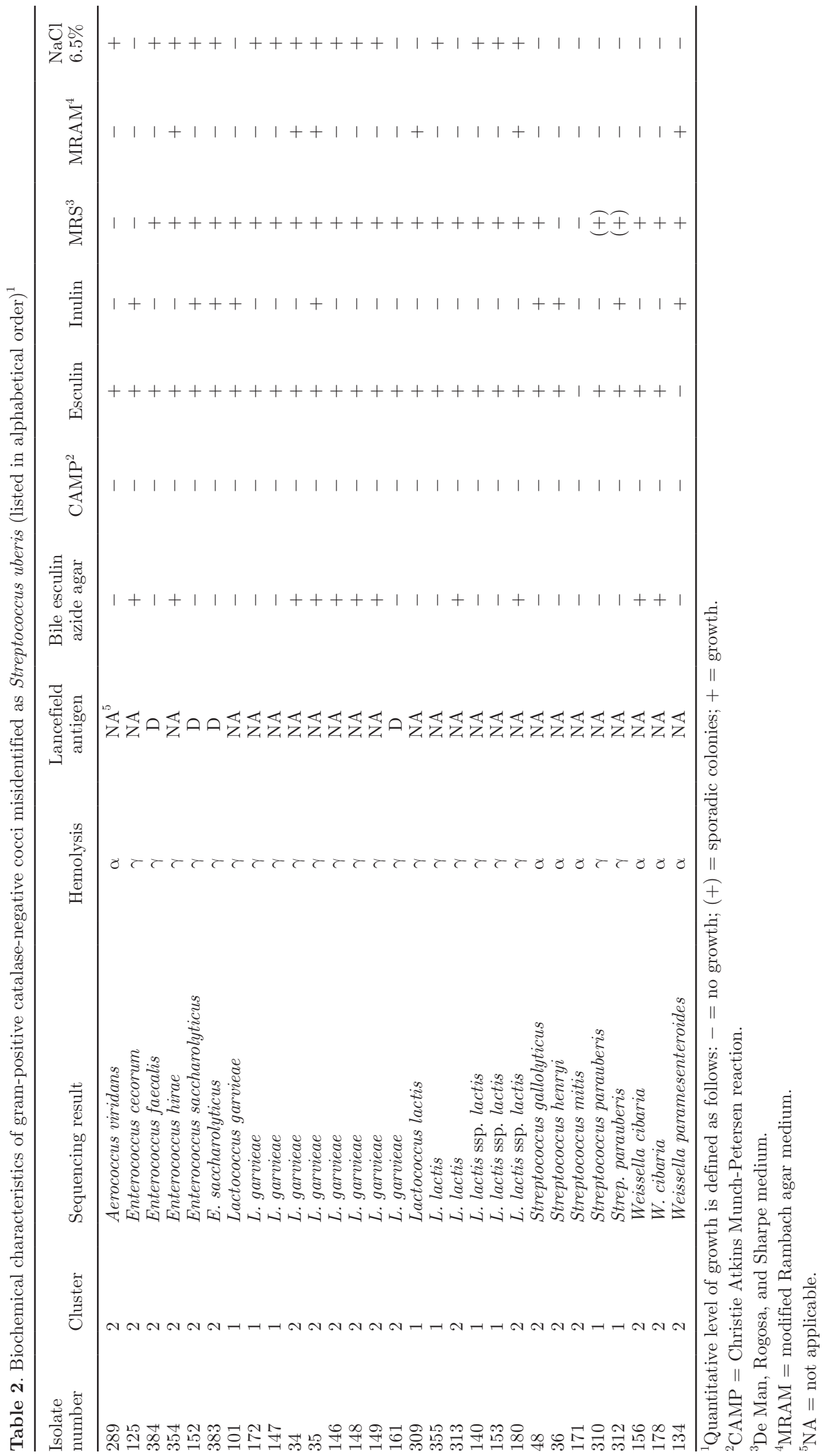

Journal of Dairy Science Vol. 100 No. 2, 2017 
Table 3. Evaluation of the modified Rambach agar medium method ${ }^{1}$

\begin{tabular}{lcccccccc}
\hline Item & $\begin{array}{c}\text { True } \\
\text { positives }\end{array}$ & $\begin{array}{c}\text { True } \\
\text { negatives }\end{array}$ & $\begin{array}{c}\text { False } \\
\text { positives }\end{array}$ & $\begin{array}{c}\text { False } \\
\text { negatives }\end{array}$ & Sensitivity & Specificity & PPV & NPV \\
\hline Cluster 1 & 256 & 8 & 1 & 15 & 94.46 & 88.89 & 99.61 \\
Cluster 2 & 32 & 15 & 5 & 4 & 88.89 & 75.00 & 86.49 \\
Total & 288 & 23 & 6 & 19 & 93.81 & 79.31 & 97.96 & 54.76 \\
\hline
\end{tabular}

${ }^{1}$ Sensitivity $(\%)=$ true positives/(true positives + false negatives); specificity $(\%)=$ true negatives/(true negatives + false positives); PPV (positive predictive value, $\%)=$ true positives/(true positives + false positives); and NPV (negative predictive value, $\%$ ) $=$ true negatives/(true negatives + false negatives).

bacteriological culture of 0.4 . The AUC was $0.79(95 \%$ CI $0.70-0.87)$. The sensitivity and specificity of bacteriological culture were 88.27 and $68.97 \%$, respectively (positive predictive value $96.79 \%$, negative predictive value $35.71 \%$ ).

\section{Evaluation of MRAM and Additional Tests (MRS Agar, Inulin Broth, 6.5\% NaCl Solution)}

In cluster 1, 257 isolates showed blue-colony growth, and thus $\beta$-D-galactosidase production on MRAM. Of those, 256 were confirmed as Strep. uberis. Identification exclusively with MRAM reached a sensitivity of $94.47 \%$ and a specificity of $88.89 \%$ in this cluster. In cluster 2, 37 isolates produced $\beta$-D-galactosidase, and of those, 32 were confirmed as Strep. uberis. In this cluster, MRAM reached a sensitivity of $88.89 \%$ and a specificity of $75.00 \%$. Of all 307 isolates identified as Strep. uberis, $288(93.81 \%)$ were $\beta$-D-galactosidase-positive (Table 3 ). The results of $16 \mathrm{~S}$ and MRAM differed significantly (McNemar's test $P=0.03$ ). The $\kappa$ value was 0.59 , and the AUC was 0.85 (95\% CI 0.77-0.93).

Streptococcus uberis isolates that were $\beta$-Dgalactosidase-negative formed rosy, pale blue, or purple colonies on MRAM $(\mathrm{n}=19)$. Additional investigations revealed that these false-negative isolates showed no growth or poor growth on a lactobacilli MRS agar, and 17 isolates (89.47\%) were inulinolytic, as was expected for Strep. uberis. Eleven isolates (58.89\%) were inhibited from growing in the presence of $6.5 \% \mathrm{NaCl}$.

\section{Comparison of Methods and Identification Accuracy}

For all isolates, the Cohen's $\kappa$ coefficient between bacteriological culture and MRAM was 0.29 ; between $16 \mathrm{~S}$ and 1 test-independent identification was 0.57 (AUC 0.74, 95\% CI 0.64-0.83); and between $16 \mathrm{~S}$ and identification by both methods simultaneously was 0.45 (AUC 0.90, 95\% CI 0.86-0.94).

Correctness of identification for isolates in cluster 1 was not significantly different between MRAM application and conventional methods used in routine diagnosis (McNemar's test $P=0.210$ ), but the difference between methods for isolates in cluster 2 was significant $(P<0.001)$.

In cluster 1, identification of Strep. uberis with conventional biochemical methods reached an accuracy of $96.79 \%$. By using only MRAM, an accuracy of $94.29 \%$ was achieved. Biochemical tests failed for atypical isolates in cluster 2 (accuracy of $64.29 \%$ ), whereas MRAM presented higher accuracy (83.93\%). When combined with routine diagnosis, the use of MRAM as a second-

Table 4. Characteristics of identification methods used for Streptococcus uberis IMI (reference method $16 \mathrm{~S}$ rRNA gene sequencing)

\begin{tabular}{llcccc}
\hline Method & Cluster & $\mathrm{n}^{1}$ & $\begin{array}{c}\text { Correct } \\
\text { identification } \\
(\text { no. })\end{array}$ & $\begin{array}{c}\text { Accuracy } \\
(\%)\end{array}$ & $\begin{array}{c}95 \% \mathrm{CI}^{3} \\
(\%)\end{array}$ \\
\hline Bacteriological culture & 1 & 280 & 271 & 96.79 & $94.72-98.85$ \\
& 2 & 56 & 36 & 64.29 & $51.74-76.84$ \\
MRAM $^{4}$ & $1+2$ & 336 & 307 & 91.37 & $88.37-94.37$ \\
& 1 & 280 & 264 & 94.29 & $91.57-97.00$ \\
Combination & 2 & 56 & 47 & 83.93 & $74.31-93.55$ \\
& $1+2$ & 336 & 310 & 92.26 & $89.40-95.12$ \\
& $1+2$ & 336 & 318 & 94.64 & $92.24-97.05$ \\
\hline
\end{tabular}

${ }^{1} \mathrm{n}=$ number of isolates.

${ }^{2}$ Accuracy $p(\%)=($ true positives + true negatives $) / \mathrm{n} \times 100$.

${ }^{3}$ Where $95 \% \mathrm{CI}=p \pm 1.96 \times \sqrt{\frac{p \times(1-p)}{n}}$.

${ }^{4} \mathrm{MRAM}=$ modified Rambach agar medium. 
ary test for identification of atypical Strep. uberis isolates increased the accuracy of identification to $94.64 \%$ (Table 4).

\section{DISCUSSION}

The majority of Strep. uberis isolates showed a typical biochemical profile according to the reference quality-control strain: they were catalase-negative, nonhemolytic, and esculin-positive. They failed to grow on media containing bile, and they were not typable with Lancefield antisera A, B, C, D, or G. Isolates that fulfilled these criteria could be identified with high accuracy using conventional methods. Application of MRAM did not significantly increase identification accuracy for this cluster.

All mucoid-growing isolates produced $\beta$-Dgalactosidase and were confirmed by $16 \mathrm{~S}$ sequencing as Strep. uberis, suggesting that the mucoid appearance of catalase-negative cocci can be indicative of species identity (Misra and Marshall, 1972; Fortin et al., 2003).

In contrast to cluster 1 , we observed high bacterial diversity and lack of accuracy with conventional testing in cluster 2. An inherent weakness in routine methods seems to be that the expression of characteristics varies by Strep. uberis isolate (Odierno et al., 2006; Krömker et al., 2014; Duarte et al., 2015). The routine identification procedure could be misleading with respect to the distinction between atypical Strep. uberis and other environmental streptococci species or lactic acid bacteria, particularly Lactococcus spp. (Fortin et al., 2003; Werner et al., 2014). For Strep. uberis isolates with deviating biochemical characteristics, the combined use of classical methods and MRAM significantly increased the accuracy of routine diagnosis.

To the best of our knowledge, this was the first test series applying MRAM to $16 \mathrm{~S}$ rRNA-confirmed isolates. As reported by Watts et al. (1993), 95\% of Strep. uberis isolates were determined to be positive for $\beta$-D-galactosidase production. The majority of non-Strep. uberis isolates in both clusters could have been excluded with the application of MRAM. It was not possible to differentiate between Strep. uberis and Strep. parauberis using routine identification procedures (Khan et al., 2003; Wyder et al., 2011; Krömker et al., 2014), but both Strep. parauberis isolates failed to show blue-colored colony growth on MRAM. Although MRAM identification is moderately discriminatory, false-negative and false-positive results occurred, decreasing its specificity. To distinguish Strep. uberis isolates (which are false-negative on MRAM) from false-positive lactic acid bacteria, culture media could be used, such as MRS agar to encourage growth of lactococci, fermentation of inulin, and growth inhibi- tion in $6.5 \% \mathrm{NaCl}$ broth. Our results further indicated that fermentation of inulin and salt tolerance could be perceived as additional diagnostic tools, but they were not sufficiently reliable to distinguish Strep. uberis from some Enterococcus, Lactococcus, or Streptococcus species (Odierno et al., 2006). Our results for salt tolerance were not consistent with the National Mastitis Council (1999), which reported that more than $90 \%$ of Strep. uberis isolates were unable to grow in a $6.5 \% \mathrm{NaCl}$ broth test.

Reliable detection of pathogens is a prerequisite for pathogen-specific therapies (Royster and Wagner, 2015). Although $16 \mathrm{~S}$ rRNA gene sequencing is clearly more accurate than phenotypic testing for identifying mastitis pathogens, it is not widely used in laboratories because of technical, cost and time constraints (Clarridge, 2004). Thus, MRAM could be particularly useful for the final identification of Strep. uberis isolates with uncertain phenotypic and biochemical properties. The major disadvantage of MRAM in routine laboratories might be that it is not available for purchase as an agar base or ready-prepared plates. For the differentiation of streptococci, MRAM application reduces the number of tests needed in routine diagnosis and saves diagnostic time and costs for species-level identification (Watts et al., 1993).

\section{CONCLUSIONS}

Routine identification of mastitis pathogens requires simple, inexpensive, but accurate methods. Based on our results for the identification of Strep. uberis and its differentiation from other lactic acid bacteria in routine diagnosis, catalase reaction, hemolysis, esculin hydrolysis, and growth on Enterococcus agar are recommended. Isolates that show a typical biochemical profile can be identified satisfactorily using these methods. For Strep. uberis isolates with divergent patterns, better accuracies can be achieved using MRAM as a follow-up test. Inulin broth, $6.5 \% \mathrm{NaCl}$ solution, and a lactobacilli medium may be used as supportive methods, but MRAM remains the most valuable tool in Strep. uberis mastitis diagnosis.

\section{ACKNOWLEDGMENTS}

The authors acknowledge the support of the Austrian Association for Buiatrics. The project was also funded by the city of Vienna through the Hochschuljubiläumsstiftung. We are grateful to Sonja Klinger for technical assistance, and to the platform biostatisticians (Alexander Tichy and Marlies Dolezal) for counseling services. The authors declare that they have no conflicts of interest. 


\section{REFERENCES}

Britten, A. M. 2012. The role of diagnostic microbiology in mastitis control programs. Vet. Clin. North Am. Food Anim. Pract. 28:187-202. https://doi.org/10.1016/j.cvfa.2012.03.006.

Clarridge, J. E., 3rd 2004. Impact of $16 \mathrm{~S}$ rRNA gene sequence analysis for identification of bacteria on clinical microbiology and infectious diseases. Clin. Microbiol. Rev. 17:840-862. https://doi. org/10.1128/CMR.17.4.840-862.2004.

CLSI. 2014. Performance Standards for Antimicrobial Susceptibility Testing: Twenty-Fourth Informational Supplement. CLSI document M100-S24. Clinical and Laboratory Standards Institute, Wayne, PA.

Duarte, C. M., P. P. Freitas, and R. Bexiga. 2015. Technological advances in bovine mastitis diagnosis: An overview. J. Vet. Diagn. Invest. 27:665-672. https://doi.org/10.1177/1040638715603087.

Fortin, M., S. Messier, J. Paré, and R. Higgins. 2003. Identification of catalase-negative, non-beta-haemolytic, gram-positive cocci isolated from milk samples. J. Clin. Microbiol. 41:106-109. https:// doi.org/10.1128/JCM.41.1.106.

Gillespie, B. E., and S. P. Oliver. 2005. Simultaneous detection of mastitis pathogens, Staphylococcus aureus, Streptococcus uberis, and Streptococcus agalactiae by multiplex real-time polymerase chain reaction. J. Dairy Sci. 88:3510-3518. https://doi.org/10.3168/jds. S0022-0302(05)73036-8.

Hillerton, J. E., and K. E. Kliem. 2002. Effective treatment of Streptococcus uberis clinical mastitis to minimize the use of antibiotics. J. Dairy Sci. 85:1009-1014. https://doi.org/10.3168/ jds.S0022-0302(02)74161-1.

Juretschko, S., G. Timmermann, M. Schmid, K. H. Schleifer, A. Pommerening-Röser, H. P. Koops, and M. Wagner. 1998. Combined molecular and conventional analyses of nitrifying bacterium diversity in activated sludge: Nitrosococcus mobilis and Nitrospiralike bacteria as dominant populations. Appl. Environ. Microbiol. 64:3042-3051

Khan, I. U., A. A. Hassan, A. Abdulmawjood, C. Lämmler, W. Wolter, and M. Zschöck. 2003. Identification and epidemiological characterization of Streptococcus uberis isolated from bovine mastitis using conventional and molecular methods. J. Vet. Sci. 4:213-224.

Krömker, V., J.-H. Paduch, D. Klocke, J. Friedrich, and C. Zinke. 2010. Efficacy of extended intramammary therapy to treat moderate and severe clinical mastitis in lactating dairy cows. Berl. Munch. Tierarztl. Wochenschr. 123:147-152.

Krömker, V., F. Reinecke, J.-H. Paduch, and N. Grabowski. 2014 Bovine Streptococcus uberis intramammary infections and mastitis. Clin. Microbiol. 03:1-7.

Lam, T., R. Olde Riekerink, O. Sampimon, and H. Smith. 2009. Mastitis diagnosis and performance monitoring: A practical approach. Ir. Vet. J. 62:S34-39. https://doi.org/10.1186/2046-0481-62-S4S34.

Lane, A. N. 1991. The solution conformations of a mutant trp operator determined by n.m.r. spectroskopy. Biochem. J. 273:383-391.

McDougall, S., T. J. Parkinson, M. Leyland, F. M. Anniss, and S. G. Fenwick. 2004. Duration of infection and strain variation in Streptococcus uberis isolated from cows' milk. J. Dairy Sci. 87:20622072. https://doi.org/10.3168/jds.S0022-0302(04)70024-7.

McHugh, M. L. 2012. Interrater reliability: The kappa statistic. Biochem. Med. (Zagreb) 22:276-282. https://doi.org/10.11613/ BM.2012.031.

Milne, M. H., A. Biggs, D. C. Barrett, F. J. Young, S. Doherty, G. T. Innocent, and J. L. Fitzpatrick. 2005. Treatment of persistent intramammary infections with Streptococcus uberis in dairy cows. Vet. Rec. 157:245-250.

Misra, B., and R. T. Marshall. 1972. Streptococcus uberis of bovine mastitis origin: Isolation, characterization, and serology of two mucoid isolates. J. Dairy Sci. 55:194-199. https://doi.org/10.3168/ jds.S0022-0302(72)85458-4.

National Mastitis Council. 1999. Laboratory Handbook on Bovine Mastitis. National Mastitis Council, Madison, WI.
Odierno, L., L. Calvinho, P. Traverssa, M. Lasagno, C. Bogni, and E. Reinoso. 2006. Conventional identification of Streptococcus uberis isolated from bovine mastitis in Argentinean dairy herds. J. Dairy Sci. 89:3886-3890. https://doi.org/10.3168/jds.S00220302(06)72431-6.

Oliver, S. P., R. A. Almeida, B. E. Gillespie, S. J. Headrick, H. H. Dowlen, D. L. Johnson, K. C. Lamar, S. T. Chester, and W. M. Moseley. 2004. Extended ceftiofur therapy for treatment of experimentally-induced Streptococcus uberis mastitis in lactating dairy cattle. J. Dairy Sci. 87:3322-3329. https://doi.org/10.3168/jds. S0022-0302(04)73468-2.

Oliver, S. P., R. A. Almeida, B. E. Gillespie, S. J. Ivey, H. Moorehead, P. Lunn, H. H. Dowlen, D. L. Johnson, and K. C. Lamar. 2003 Efficacy of extended pirlimycin therapy for treatment of experimentally induced Streptococcus uberis intramammary infections in lactating dairy cattle. Vet. Ther. 4:299-308.

Raemy, A., M. Meylan, S. Casati, V. Gaia, B. Berchtold, R. Boss, A. Wyder, and H. U. Graber. 2013. Phenotypic and genotypic identification of streptococci and related bacteria isolated from bovine intramammary infections. Acta Vet. Scand. 55:53. https:// doi.org/10.1186/1751-0147-55-53.

Royster, E., and S. Wagner. 2015. Treatment of mastitis in cattle. Vet. Clin. North Am. Food Anim. Pract. 31:17-46. https://doi. org/10.1016/j.cvfa.2014.11.010.

Schukken, Y., M. E. Charter, B. Moslock-Carter, N. Belomestnykh, and R. Zadoks. 2009. Strep species: To differentiate or not to differentiate? DairyBusiness East. 5:18-19.

Swinkels, J. M., V. Krömker, and T. J. Lam. 2014. Efficacy of standard vs. extended intramammary cefquinome treatment of clinical mastitis in cows with persistent high somatic cell counts. J. Dairy Res. 81:424-433. https://doi.org/10.1017/S0022029914000442.

Tassi, R., T. N. McNeilly, J. L. Fitzpatrick, M. C. Fontaine, D. Reddick, C. Ramage, M. Lutton, Y. H. Schukken, and R. N. Zadoks, 2013. Strain-specific pathogenicity of putative host-adapted and nonadapted isolates of Streptococcus uberis in dairy cattle. J. Dairy Sci. 96:5129-5145. https://doi.org/10.3168/jds.2013-6741.

Teixeira, L. M., V. L. Merquior, M. C. Vianni, M. G. Carvalho, S. E Fracalanzza, A. G. Steigerwalt, D. J. Brenner, and R. R. Facklam. 1996. Phenotypic and genotypic characterization of atypical Lactococcus garvieae isolates isolated from water buffalos with subclinical mastitis and confirmation of $L$. garvieae as a senior subjective synonym of Enterococcus seriolicida. Int. J. Syst. Bacteriol. 46:664-668. https://doi.org/10.1099/00207713-46-3-664.

Walsh, P. S., D. A. Metzger, and R. Higuchi. 1991. Chelex 100 as a medium for simple extraction of DNA for PCR-based typing from forensic material. Biotechniques 10:506-513. https://doi. org $/ 10.2144 / 000113897$.

Watts, J. L., S. A. Salmon, and R. J. Yancey. 1993. Use of modified Rambach agar to differentiate Streptococcus uberis from other mastitis streptococci. J. Dairy Sci. 76:1740-1743. https://doi. org/10.3168/jds.S0022-0302(93)77506-2.

Werner, B., P. Moroni, G. Gioia, L. Lavín-Alconero, A. Yousaf, M. E. Charter, B. M. Carter, J. Bennett, D. V. Nydam, F. Welcome, and Y. H. Schukken. 2014. Short communication: Genotypic and phenotypic identification of environmental streptococci and association of Lactococcus lactis ssp. lactis with intramammary infections among different dairy farms. J. Dairy Sci. 97:6964-6969. https:// doi.org/10.3168/jds.2014-8314.

Wyder, A. B., R. Boss, J. Naskova, T. Kaufmann, A. Steiner, and H. U. Graber. 2011. Streptococcus spp. and related bacteria: Their identification and their pathogenic potential for chronic mastitisA molecular approach. Res. Vet. Sci. 91:349-357. https://doi. org/10.1016/j.rvsc.2010.09.006

Zadoks, R. N., B. E. Gillespie, H. W. Barkema, O. C. Sampimon, S. P. Oliver, and Y. H. Schukken. 2003. Clinical, epidemiological and molecular characteristics of Streptococcus uberis infections in dairy herds. Epidemiol. Infect. 130:335-349. 